\title{
Perseveration of associative strength in rabbit nictitating membrane response conditioning
}

\author{
MICHAEL J. SCAVIO, JR., ROBERT T. ROSS, and LYNDA M. McLEOD \\ California State University, Fullerton, California
}

\begin{abstract}
The present experiment used a transfer-of-training procedure in rabbit nictitating membrane response (NMR) conditioning to determine whether a retention interval and/or extinction could reduce associative strength. The experimental design required that groups receive $0,3,15,45$, 150 , or 240 CS-US pairings in Stage 1. Next, the groups were given, in succession, a 10-day retention interval and 480 CS-alone trials. In Stage 2, all groups obtained 240 CS-US pairings for NMR conditioning. Another group was also employed and received only the 240 CS-US pairings in Stage 2. The results indicated that 15 to 240 CS-US pairings in Stage 1 substantially enhanced NM CR performance in Stage 2 despite the interpolation of the retention interval and CS-alone trials. When 3 CS-US pairings had been given in Stage 1, no augmentation in the NM CR performance rate occurred in Stage 2. However, the 3 CS-US pairings were effective in prohibiting the 480 CS-alone trials from retarding subsequent NM CR performance. Without any pairings in Stage 1, the 480 CS-alone trials produced strong latent inhibition of NMR conditioning in Stage 2. The data were used to support the theoretical view that associative strength resulting from CS-US pairings is relatively permanent. Moreover, the findings were relevant for an evaluation of Pearce and Hall's (1980) recent statements concerning CS associability and the relationship between excitatory and inhibitory processes.
\end{abstract}

An unresolved issue among learning theorists concerns the perseveration of associative strength. On one side of the question are those (e.g., Hull, 1943; Kimble, 1961; Pearce \& Hall, 1980) who have argued that associative strength is relatively permanent. However, others have taken the opposite position that associative strength can be eliminated by a variety of manipulations. For example, the imposition of a retention interval after conditioning has been treated as a means for removing associative strength (e.g., Gleitman, 1971; Thorndike, 1911). According to Gleitman (p. 37), the "disuse" of associations may permit the time-dependent decomposition of the neural substrates that encode learning. Furthermore, extinction has been considered as another procedure leading to the reduction of associative strength (e.g., Mackintosh, 1975; Rescorla \& Wagner, 1972). According to Rescorla and Wagner (p. 80), the drops in conditioned performance in extinction are due to the CS losing associative strength, since the US is no longer predicted.

The opposing arguments concerning the perseveration of associative strength were assessed in the present transfer-of-training experiment employing

\footnotetext{
The research was supported by NIMH Grant 31935-01. Robert T. Ross is now at the University of Iowa. We also gratefully thank John W. Moore and Douglas Navarick for their readings of the manuscript and Pamela Scavio for data-collection assistance. Requests for reprints should be addressed to: Michael J. Scavio, Department of Psychology, California State University, Fullerton, Fullerton, California 92634.
}

the procedures for rabbit nictitating membrane response (NMR) conditioning. Thus, independent groups initially received $0,3,15,45,150$, or 240 CS-US pairings in Stage 1. Next, all groups were given, in succession, a 10-day retention interval and $480 \mathrm{CS}$-alone presentations. Finally, all groups were given 240 CS-US pairings in Stage 2 for the resumption of NMR conditioning. Another group, serving as an additional control, received only the Stage 2 pairings. Predictions may be made for the outcomes of the present experiment from the alternative views regarding the perseveration of associative strength. If the Stage 1 training levels produce relatively permanent associative strength, then facilitation of NM CS performance in Stage 2 could be expected despite the interpolation of the retention interval and the CS-alone presentations. However, if associative strength resulting from Stage 1 training is dissipated by the retention interval and/or the CS-alone deliveries, then the occurrence of positive carry-over effects upon NM CR performance in Stage 2 should be precluded.

\section{METHOD}

\section{Subjects}

Forty-two male and female New Zealand albino rabbits served as the subjects. The average age and weight of the rabbits were 90 days and $2.25 \mathrm{~kg}$.

\section{Apparatus}

The fabrication of the conditioning apparatus followed Gormezano's (1966) specifications. Accordingly, six condition- 
ing chambers were constructed from legal-sized filling cabinets. In each chamber, a stimulus panel was attached to the front side. The panel contained a pair of $24-\mathrm{V}$ dc, $10-\mathrm{W}$ lamps mounted behind diffusion glass for continuous illumination and an audio speaker for transmitting the CS. Plexiglas boxes with variableposition backplates and yoke collars were used to restrain the rabbits while they were in the chambers.

Movement of the nictitating membrane was measured for each rabbit by a microtorque potentiometer that was fastened to a muzzle device securely locked to a ring looped over the pinnae. The NMR was monitored in the following manner. A counterbalanced wire lever, attached to the potentiometer's rotary shaft, issued a length of silk thread that was tied to a small metal hook. In turn, the hook was connected to a suture placed in the lateral edge of the right nictitating membrane. Movements of the membrane were transduced by the potentiometer into linear voltage changes that were first amplified and then recorded by an analogto-digital (AD-12) converter of a PDP-12 computer.

The CS was a $500-\mathrm{msec}, 1,000-\mathrm{Hz}$ tone of $86-\mathrm{dB}$ (re: $20 \mu \mathrm{N} / \mathrm{m}^{2}$ ) superimposed on a $72-\mathrm{dB}$ white-noise field. The US was a 50msec, 4-mA, 60-Hz electrical shock delivered through stainless steel wound clips placed in the skin $10-\mathrm{mm}$ apart and $15-\mathrm{mm}$ behind the right eye. Finally, the PDP-12 computer was programmed to present the CS and US as well as to record the NMR (Bissell \& Scavio, 1974).

\section{Procedure}

Two days following arrival from the supplier, each rabbit received a suture in the right nictitating membrane made with 00 monofilament surgical thread. After 2 more days, each rabbit was fitted with a potentiometer and placed in the conditioning apparatus for a 40-min adaptation session free of the CS and the US. On the following day, Stage 1 was initiated by randomly assigning six subjects to each of seven groups. Five of these groups (labeled P-3, P-15, P-45, P-150, and P-240) received, respectively, 3, 15, 45, 150, and 240 CS-US pairings in Stage 1. The CS-US pairings for each group were divided equally across three daily sessions. Upon the conclusion of Stage 1, the groups received a 10-day retention interval, continuously spent in the home cages, and $480 \mathrm{CS}$-alone presentations, divided equally across six daily sessions. Finally, Stage 2 was undertaken on the next day after the completion of the CS-alone presentations. In Stage 2 , all groups received 240 CS-US pairings divided equally across three daily sessions.

Two control groups were also used. Following the adaptation day, control Group C-0, in lieu of CS-US pairings, was confined in the apparatus on each of the 3 days of Stage 1. Each confinement period matched the length (i.e., $80 \mathrm{~min}$ ) of the daily training sessions given to Group P-240 in Stage 1. Thereafter, Group C-0 was given the 10-day stay in the home cages, the six daily sessions of CS-alone presentations (i.e., 80 trials daily), and the three daily sessions of CS-US pairings in Stage 2 (i.e., 80 trials daily). After the adaptation day, the other control (Group C-00) was also housed in the apparatus without CS and US deliveries on each of 3 days for $80 \mathrm{~min}$ daily. Then, Group $\mathrm{C}-00$ was given the 10-day stay in the home cages and, in place of the CS-alone presentations, six more daily sessions of apparatus confinement, with each period lasting the time (i.e., $80 \mathrm{~min}$ ) required to present the daily CS-alone trials. Finally, Group $C-00$ received the three daily sessions of CS-US pairings in Stage 2 (i.e., 80 trials daily).

The interstimulus interval for all CS-US pairings was $500 \mathrm{msec}$. The intertrial intervals for the CS-US pairings and the CS-alone presentations were randomized at values of 50 and $70 \mathrm{sec}$, with a mean of $60 \mathrm{sec}$. When Groups $\mathrm{C}-0$ and $\mathrm{C}-00$ were confined in the apparatus without trials, observations of NMR activity were taken at times corresponding to the delivery of the CS for Group P-240. Membrane extensions of at least $.5 \mathrm{~mm}$ during the 500-msec CS were considered to be CRs. Also, membrane extensions meeting the $.5-\mathrm{mm}$ criterion during the 500 -msec ob- servation intervals given to Groups $\mathrm{C}-0$ and $\mathrm{C}-00$ were used to index base-level activity.

\section{RESULTS}

The extreme left panel of Figure 1 depicts the daily NM CR percentages on the CS-US pairings given to Groups P-3, P-15, P-45, P-150, and P-240 in Stage 1 . The panel also shows the daily percentages of base-level NMRs during the observation intervals given to Groups $\mathrm{C}-0$ and $\mathrm{C}-00$. Examination of the panel indicates that the NM CR performances for Groups P-45, P-150, and P-240 varied directly with the number of pairings in Stage 1. In contrast, Groups P-3 and P-15 displayed no NM CR acquisition, since their performances matched the low NMR base levels obtained for Groups C-0 and $\mathrm{C}-00$. The overall NM CR percentages for Groups $P-3, P-15, P-45, P-150$, and $P-240$ averaged $1 \%$, $3 \%, 20 \%, 45 \%$, and $67 \%$, respectively, and the overall percentages of base-level NMRs for Groups C-0 and C-00 averaged $1 \%$ and $2 \%$, respectively. These performance differences among the groups were significant $[F(6,35)=34.92, p<.01]$.

The middle panel of Figure 1 illustrates the daily NM CR percentages on the CS-alone trials given to Groups C-0, P-3, P-15, P-45, P-150, and P-240. The panel also includes the daily percentages of baselevel NMRs found in the observation intervals given to Group C-0. The panel shows similar losses in NM CR performance for Groups $P-45, P-150$, and P-240 over the daily sessions. During the middle sessions, Groups P-3 and P-15 showed small, transient increases in NM CR performances. Finally, Group C-0 displayed very few NM CRs, as indicated by the correspondence to the NMR base level set by Group C-00. The overall NM CR percentages for Groups $C-0$,

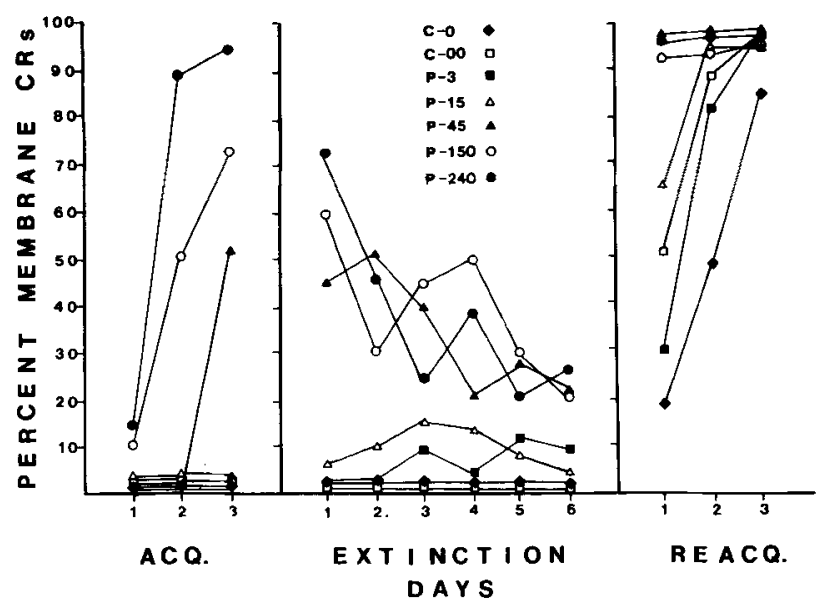

Figure 1. Group percentages of membrane CRs for the acquisition (Stage 1), extinction (CS-alone trials), and reacquisition (Stage 2) days of the experiment. 
P-3, P-15, P-45, P-150, and P-240 averaged 3\%, $7 \%, 10 \%, 36 \%, 43 \%$, and $39 \%$, respectively; and the overall percentage of base-level NMRs for Group $C-00$ was $2 \%$. These group differences $[F(6,35)$ $=7.96, \mathrm{p}<.01]$, along with the decreases in $\mathrm{NM}$ $C R$ performance over days $[F(5,175)=4.10$, $p<$ $.01]$, were significant.

The extreme right panel of Figure 1 presents the daily NM CR percentages for all groups in Stage 2. Groups P-15, P-45, P-150, and P-240 clearly showed enhanced NM CR performances relative to Group $\mathrm{C}-00$, which had no training prior to Stage 2 . Therefore, 15 to $240 \mathrm{CS}$-US pairings in Stage 1 produced positive carry-over effects upon NM CR performance in Stage 2 despite the interpolation of the 10-day retention interval and the $480 \mathrm{CS}$-alone trials. Group P-3 represented the only training condition of Stage 1 that did not surpass the performance of Group C-00 in Stage 2. Nevertheless, Group P-3 displayed a much higher NM CR rate in Stage 2 than did Group C-0, which received the $480 \mathrm{CS}$-alone trials without any CS-US pairings being given in Stage 1 . Consequently, 3 CS-US pairings in Stage 1 were sufficient to offset the pronounced inhibitory effects of the $480 \mathrm{CS}$-alone trials upon NMR conditioning in Stage 2. The overall NM CR percentages for Groups $\mathrm{C}-00, \mathrm{P}-3, \mathrm{P}-15, \mathrm{P}-45, \mathrm{P}-150, \mathrm{P}-240$, and $\mathrm{C}-0$ averaged $73 \%, 70 \%, 88 \%, 96 \%, 96 \%, 93 \%$, and $50 \%$, respectively, in Stage 2 . The differences among the group means, initially established to be reliable $[F(6,35)$ $=10.59, \mathrm{p}<.01]$, were further assessed by a NewmanKeuls comparison test. Groups P-15, P-45, P-150, and P-240, which were not significantly different (ps $>.05$ ), were above (ps $<.05$ ) Groups P-3 and $\mathrm{C}-00$, which in turn were not significantly different $(p>.05)$. Finally, Group $C-0$ was below all others (ps<.05).

\section{DISCUSSION}

The experiment has revealed that associative consequences in NMR conditioning have a high degree of stability. Thus, 15 to 240 CS-US pairings in Stage 1 produced positive carry-over effects for NM CR performance in Stage 2 despite the interpolation of a 10-day retention interval and $480 \mathrm{CS}$-alone presentations delivered over six additional daily sessions. When 3 CS-US pairings were given in Stage 1, no enhancement of Stage 2 performance was obtained. However, the 3 CS-US pairings in Stage 1 were able to eliminate the inhibitory potential of the $480 \mathrm{CS}$ alone presentations upon NM CR performance in Stage 2. Without any Stage 1 pairings, the $480 \mathrm{CS}$ alone trials induced strong latent inhibition (Lubow \& Moore, 1959) of NM CR performance in Stage 2.

The present results can be used to address the theoretical issue concerning the perseveration of asso- ciative strength. The positive carry-over effects of 15 to 240 CS-US pairings and the ability of only 3 CS-US pairings to remove the inhibitory effects of $480 \mathrm{CS}$-alone trials are consistent with positions (e.g., Hull, 1943; Kimble, 1961; Pearce \& Hall, 1980) accepting the relative permanence of associative strength throughout its entire range of values. Consequently, the failure of the 10-day retention interval and the $480 \mathrm{CS}$-alone presentations to disrupt the training effects of Stage 1 suggests that disuse (e.g., Gleitman, 1971; Thorndike, 1911) and extinction (e.g., Mackintosh, 1975; Rescorla \& Wagner, 1972) do not serve to obliterate associative strength. Furthermore, the conclusion that the retention interval and the CS-alone trials do not decrement associative strength can be supported by other work. Thus, several investigators (e.g., Donahoe \& Marrs, 1982; Hilgard \& Marquis, 1935; Hoffman, Fleshler, \& Jensen, 1963; Wendt, 1937) have found that acquired responses are effectively retained over retention intervals stretching over several months. In addition, other researchers (e.g., Brodgen, Lipman, \& Culler, 1938; Hilgard \& Marquis, 1935; Pavlov, 1927) have consistently observed that the reacquisition of conditioned responses following extinction requires fewer trials than does original acquisition.

The present outcomes are also relevant for an evaluation of assertions made by Pearce and Hall (1980) in their recent theory of Pavlovian conditioning. Specifically, the data can be used to assess Pearce and Hall's treatments of latent inhibition and extinction. Pearce and Hall relate the occurrence of latent inhibition to changes in the "associability" of the CS. In turn, associability $\left(\alpha_{A}\right)$ is defined by the absolute discrepancy between the maximum amount of associative strength $(\lambda)$ supported by the US and the current amount of associative strength $\left(V_{A}\right)$ attached to the $C S$. In equation form, the associability of the CS is represented as: $\alpha_{A}=\left|\lambda-V_{A}\right|$. Regarding latent inhibition, presentations of the CS before the start of conditioning trials are considered to produce an $\alpha_{A}$ of zero, since the US is necessary to determine the value of $\lambda$ in the defining equation. As the equation indicates, $\alpha_{\mathrm{A}}$ remains at zero if $\lambda$ is also at zero. Moreover, Pearce and Hall $\left(1980\right.$, p. 539) favor the view that $\alpha_{A}$ is controlled by the values of $V_{\mathrm{A}}$ and $\lambda$ on the last presentations of the CS and US. Therefore, one CS-US pairing is predicted to be sufficient for the total removal of latent inhibition effects no matter how many preceding CS-alone deliveries had been given.

In contrast with Pearce and Hall's proposal, the present results suggest that latent inhibition effects cannot be dispelled by 1 CS-US pairing. The 480 CS-alone trials given to Group C-0 without any previous training in Stage 1 severely retarded NM CR performance over the entire $240 \mathrm{CS}$-US pairings of 
Stage 2. Finally, Pearce and Hall (1980, p. 548) acknowledge in the summary section of their theoretical paper that the strength of latent inhibition might summate over all previous CS-alone presentations. Thus 1 CS-US pairing would be insufficient for removing latent inhibition effects upon subsequent acquisition. This alternative proposal appears to be more accurate than the assumption developed in the main body of the paper that latent inhibition is always a temporary influence.

To explain extinction effects, Pearce and Hall rely upon the postulation of inhibitory associative strength $\left(\overline{\mathrm{V}}_{\mathrm{A}}\right)$, which is assumed to have a subtractive relationship with excitatory associative strength $\left(V_{A}\right)$ in determining the amount of conditioned performance. Regarding the specific properties of innibitory associative strength, Pearce and Hall consider that $\overline{\mathbf{V}}_{\mathbf{A}}$ can only be established after the formation of $V_{A}$. Furthermore, the limit to the growth of $\bar{V}_{A}$ over extinction trials is determined by the value of $v_{A}$. When $v_{A}$ and $v_{A}$ become equal, $\alpha_{A}$ is then assumed to be at zero. Therefore, not only do CRs fail to occur when $V_{A}$ and $\bar{v}_{A}$ become equal, but also no further increments in $\overrightarrow{\mathrm{V}}_{\mathrm{A}}$ can occur over additional extinction trials, since CS associability has been removed.

Turning to the present outcomes, Pearce and Hall's (1980) position would expect that $480 \mathrm{CS}$-alone deliveries after only $15 \mathrm{CS}$-US pairings ensure the equality of $\vec{v}_{A}$ and $V_{A}$. Therefore, the associability of the CS should have been reduced to zero. Under these circumstances, no positive carry-over effects of the 15 pairings would be predicted for NM CR performance in Stage 2 . However, as previously seen, the 15 pairings markedly enhanced NM CR performance in Stage 2 despite the interpolation of $\mathbf{4 8 0}$ CS-alone presentations as well as a 10-day retention interval. Consequently, Pearce and Hall's subtractive relationship between excitatory and inhibitory associative strengths does not appear to be present upon the resumption of CS-US pairings after extinction. Instead, the current findings suggest that the inhibitory influences, accounting for $C R$ performance losses in extinction, are rapidly removed when CS-US pairings are reinstated. Moreover, the dominance of excitatory over inhibitory processes when CS-US pairings are returned apparently requires relatively few initial CS-US pairings. As the experiment has revealed, 3 CS-US pairings in Stage 1 were remarkable in eliminating the inhibitory potential of the $480 \mathrm{CS}$-alone trials upon NM CR performance in Stage 2. When 15 CS-US pairings were employed in Stage 1, no NM CR acquisition occurred. Yet, despite the interpolation of the $480 \mathrm{CS}$-alone presentations, the 15 CS-US pairings equalled the effects of 240 CS-US pairings in Stage 1 for the facilitation of NM CR performance in Stage 2.

\section{REFERENCES}

Bissell, H. S., \& Scavio, M. J., JR. A minicomputer program for the resolution of response frequency and latency in classical conditioning preparations. Behavior Research Methods of Instrumentation, 1974, 6, 439-442.

Brodgen, W. J., Lipman, E. A., \& Culler, E. The role of incentive in conditioning and extinction. American Journal of Psychology, 1938, 51, 109-117.

Donahoe, J. W., \& Marrs, D. P. A 12-year retention of stimulus and schedule control. Bulletin of the Psychonomic Society, 1982, 19, 184-186.

Gleitman, H. Forgetting of long-term memories in animals. In W. K. Honig \& P. D. R. James (Eds.), Animal memory. New York: Academic Press, 1971.

Gormezano, I. Classical conditioning. In J. B. Sidowski (Ed.), Experimental methods and instrumentation in psychology. New York: McGraw-Hill, 1966.

Hilgard, E. R., \& Marquis, D. G. Acquisition, extinction, and retention of conditioned lid responses to light in dogs. Journal of Comparative Psychology, 1935, 19, 29-58.

Hoffman, H. S., Fleshler, M., \& Jensen, P. Stimulus aspects of aversive controls: The retention of conditioned suppression. Journal of the Experimental Analysis of Behavior, $1963,6,575-583$.

HuL., C. L. Principles of behavior. New York: Appleton-CenturyCrofts, 1943.

Kimble, G. A. Hilgard and Marquis' conditioning and learning. New York: Appleton-Century-Crofts, 1961.

Lubow, R. E., \& Moore, A. U. Latent inhibition: The effect of nonreinforced pre-exposure of the conditioned stimulus. Journal of Comparative and Physiological Psychology, 1959, 52, 415-419.

Mackintosh, N. J. A theory of attention: Variation in the associability of stimuli with reinforcement. Psychological Review, 1975, 82, 276-298.

Pavlov, I. P. Conditioned reflexes. London: Oxford University Press, 1927.

Pearce, J. M., \& Hall, G. A model for Pavlovian learning: Variations in the effectiveness of conditioned but not of unconditioned stimuli. Psychological Review, 1980, 87, 532-552.

Rescorla, R. A., \& Waaner, A. R. A theory of Pavlovian conditioning: Variations in the effectiveness of reinforcement and non-reinforcement. In A. H. Black \& W. F. Prokasy (Eds.), Classical conditioning $I I$. New York: Appleton-Century-Crofts, 1972.

Thorndike, E. L. Animal intelligence. New York: Macmillan, 1911.

WENDT, G. R. Two and one-half year retention of a conditioned response. Journal of General Psychology, 1937, 17, 178-180.

(Manuscript received May 24, 1982; revision accepted for publication August 16, 1982.) 